\title{
Ensinando história: produção de uma sequência didática sobre as representações do negro no Brasil
}

\author{
Mário Cézar Alves Ferreira * \\ Zenaide de Fátima Dante Correia Rocha ${ }^{* *}$ \\ Marilu Martens Oliveira ${ }^{* * *}$
}

\section{Resumo}

Neste trabalho o objetivo principal é apresentar a produção e a aplicação de uma sequência didática como produto educacional para a apropriação do conhecimento sobre as relações étnico-raciais no Brasil, no ensino de História. Os conceitos de representação, apropriação e práticas culturais da Nova História balizaram a construção da análise. Buscou-se, durante a aplicação, discutir o processo de exclusão social dos afrobrasileiros e as representações do negro no cinema nacional a partir de filmes realizados em diferentes períodos da história do Brasil, procurando superar as visões estereotipadas e discriminatórias. A pesquisa foi realizada em uma escola pública de Londrina, Paraná, com uma turma de trinta e cinco estudantes, do terceiro ano do Ensino Médio. Nesta pesquisa-ação, os dados foram coletados mediante atividades escritas, orais e gravações. Para os planos de aula, foram selecionados o quadro A Redenção de Can (1895), a música A favela vai abaixo (1927) e quatro filmes, sendo eles: O Despertar da Redentora (1942), Orfeu do Carnaval (1959), Rio Babilônia (1982) e Besouro (2009). A pesquisa partiu do seguinte problema: Como as sequências didáticas de História, desenvolvidas a partir de diferentes linguagens, podem contribuir para a desconstrução do preconceito racial no ambiente escolar? $\mathrm{O}$ fulcro das atividades foi discutir o racismo e as estereotipias sobre o negro, presentes em filmes nacionais, buscando aprimorar o olhar crítico dos estudantes sobre os discursos fílmicos, além de promover a discussão e a leitura histórico-social da contribuição dos negros para a cultura brasileira. Os resultados da pesquisa estão em processo de análise. Espera-se que esta investigação, ao ser concluída, possa contribuir para a implementação da Lei 10 639/03, podendo ser utilizada por professores e outros agentes sociais tanto como material de apoio quanto para instrumento de reflexão sobre as práticas pedagógicas referentes à temática racial no ambiente escolar.

Palavra-chave: ensino de história, sequência didática, representações do negro.

\footnotetext{
Mestrando pelo Programa de Pós-Graduação em Ensino de Ciências Humanas, Sociais e da Natureza da Universidade Tecnológica Federal do Paraná, Campus Londrina. E-mail: mariocezara@hotmail.com

** Mestranda pelo Programa de Pós-Graduação em Ensino de Ciências Humanas, Sociais e da Natureza da Universidade Tecnológica Federal do Paraná, Campus Londrina. E-mail: zenaiderocha@utfpr.edu.br

*** Programa de Pós-Graduação em Ensino de Ciências Humanas, Sociais e da Natureza da Universidade Tecnológica Federal do Paraná, Campus Londrina PPGEN/UTFPR-LD. E-mail: marilu@utfpr.edu.br
} 
Teaching history: production of a didatic sequence on representations of black people in Brazil

\begin{abstract}
In this paper the main objective is to present the production and application of a didactic sequence as an educational product for the appropriation of knowledge on ethnic-racial relations in Brazil, when teaching history. The concepts of representation, appropriation and cultural practices of the New History assist in the construction of guidelines. During the procedure, we sought to discuss the process of social exclusion of Afro-Brazilians and representations of black people in Brazilian movies made during different historical periods in Brazil, with a view to overcoming stereotypical and discriminatory views. The survey was conducted in a public school in Londrina, Paraná, with a group of thirty-five $3^{\text {rd }}$ year high school students. In this action research, data was collected through written, oral and recorded activities. For the lesson plans, we selected the painting Redemption of Cam (1895), the song "A favela vai abaixo" (1927) and four movies, namely: "O Despertar da Redentora" (1942), "Orfeu do Carnaval" (1959), "Rio Babilônia" (1982) and "The Beetle" (2009). The study started from the following premise: How can historical didactic sequences, drafted in different languages, contribute to the deconstruction of racial prejudice in the school environment? The focus of activities was to discuss racism and stereotypes of black people in national films in order to improve the critical thinking of students on film themes, and stimulate discussion on the socio-historical reading of the contribution of black people to Brazilian culture. The research results are in the process of analysis. It is hoped that this research, when completed, will contribute to the implementation of Law 10.639/03 and be used by teachers and other social actors both as support material and a tool for reflection on pedagogical practices involving racial issues in the school environment.
\end{abstract}

Keywords: history teaching, didactic sequence, representations of black people.

Introdução

Este trabalho tem como objetivo principal apresentar a produção e aplicação de uma sequência didática como produto educacional para a apropriação do conhecimento tanto de professores quanto de estudantes sobre as relações étnico-raciais no Brasil, no ensino de história. Pretende-se, com esse procedimento, discutir as origens do racismo e da exclusão social do negro e construir, com os estudantes, um olhar crítico sobre como a desigualdade social entre negros e brancos pode ser observada também no cinema que, como um produto social, é também um reflexo da sociedade em que foi produzido (FERRO, 1992).

De caráter qualitativo, a investigação caracterizou-se como uma pesquisa 
ação, cujo enfoque é a produção e aplicação de uma sequência didática desenvolvida durante o ano de 2014, com uma turma de trinta e cinco estudantes do terceiro ano do ensino médio, numa escola pública de Londrina/Paraná, por meio de sete encontros, sendo um a cada semana. A realização da coleta de dados ocorreu a partir de atividades diversas, bem como as anotações e gravações foram pensadas com a finalidade de buscar indícios sobre a dinâmica de condução da sequência didática de modo que fosse possível avaliar também, o processo de aprendizagem dos estudantes.

Com base na trajetória descrita, foi estabelecido o seguinte problema de pesquisa: Como as sequências didáticas de História, desenvolvidas a partir de diferentes linguagens podem contribuir para a desconstrução do preconceito racial no ambiente escolar? Para os planos de aula foram selecionados o quadro Redenção de Can (1895), a Canção A favela vaia abaixo (1927) e quatro filmes, sendo eles: O despertar da redentora (1942), um trecho de Orfeu do Carnaval (1959), um trecho de Rio Babilônia (1982) e Besouro (2009). Sua aplicação foi dividida em sete módulos.

\section{Representações e debates sobre o negro na historiografia brasileira}

A Lei 10 639/03, aprovada em janeiro de 2003, estabelece a obrigatoriedade da inclusão da temática História e Cultura afro-brasileira no currículo de ensino das escolas públicas e privadas, visando atender a antigas reinvindicações do Movimento Negro no Brasil. O objetivo é incentivar e promover políticas de reparação aos prejuízos históricos causados aos afro-brasileiros, por meio de ações afirmativas que valorizem a contribuição dos povos africanos na formação da cultura brasileira.

A referida lei busca promover uma mudança de postura dos professores na abordagem de temas relacionados aos africanos e afro-brasileiros, para que possam desenvolver nos estudantes novas atitudes diante das diferenças étnicas, contribuindo assim, para o combate à violência e a valorizando a paz. Deve-se lembrar que durante muito tempo, as escolas abordaram conteúdos sobre continente africano de maneira negativa, evidenciando a condição de submissão e humilhação dos negros, o que causava, muitas vezes, constrangimentos aos estudantes afrodescendentes.

Essas práticas são potencializadas, em grande parte, por representações estereotipadas caricaturais veiculadas pelos meios de comunicação e livros didáticos, produzindo práticas racistas que passam, muitas vezes, despercebidas no interior da escola. Por ocorrerem de forma velada, muitas delas são difíceis de identificar e geralmente ocorrem via palavras e atitudes que desqualificam o negro e sua cultura, expressando 
sentimentos de superioridade dos brancos em relação aos afrobrasileiros comprovando a existência de uma sociedade racialmente hierárquica e desigual.

Fonseca (2006) realizou um estudo sobre as apropriações que os livros didáticos fizeram sobre o tema da escravidão, a partir do início do século XX. Em seu objeto de estudo, a historiadora constatou que mesmo entre os manuais mais recentes, ainda permanece uma resistência em abandonar a visão reducionista de coisificação e vitimização do escravo. As analogias presentes nesses manuais permanecem calcadas na historiografia e sociologia marxista das décadas de 50 e 60 (século XX), que construíram uma visão reducionista sobre a escravidão e a vida em cativeiro. Ao focarem apenas a dimensão econômica, os autores marxistas desprezaram dimensões importantes para a compreensão da dinâmica social escravista. Essa perspectiva, segundo Fonseca, foi a que predominou e ainda permanece presente, em grande medida, nos manuais didáticos, inibindo abordagens mais incisivas e detalhadas sobre a complexidade da vida escrava no Brasil. Neles, o escravo é representado constantemente como coisa e, quase sempre, como ser incapaz de produzir história. Por essa constatação, a historiadora conclui que a produção historiográfica, presente nos livros didáticos sobre o negro, contribuiu para a cristalização, no imaginário coletivo, da ideia de que os afrobrasileiros aceitaram passivamente as imposições de arbitrariedades do regime escravocrata.

A partir da década de 1980, os debates sobre a escravidão sofreram significativas transformações no campo acadêmico, mas conforme exposto, pouco se modificou no campo do ensino de História. Novos estudos influenciados, principalmente, pelos pressupostos teórico-metodológicos da Nova História Cultural e da Nova Esquerda Inglesa, aproximaram-se da visão culturalista de Gilberto Freyre. Passou-se a enxergar o negro como sujeito da história, que nas relações cotidianas com senhores e libertos era capaz de elaborar estratégias para melhorar sua condição vida e até alcançar a tão almejada liberdade. Em contrapartida, negou-se a visão reificadora e vitimizada dos cativos. Chalhoub, ao posicionar-se contra a coisificação do escravo afirma que

A violência da escravidão não transformava os negros em seres "incapazes de ação autônoma", nem em passivos receptores de valores senhoriais, e nem tampouco em rebeldes valorosos e indomáveis. Acreditar nisso pode ser apenas uma opção mais cômoda: simplesmente desancar a barbárie social de um outro tempo traz implícita a sugestão de que somos menos bárbaros hoje em dia, de que fizemos realmente algum "progresso" dos tempos da escravidão até hoje. (CHALHOUB, 1990, p.42) 
Destaca-se, nessa época, o trabalho de Mattoso (1990) ao apresentar uma nova configuração do negro na sociedade escravista. Nele foram abordadas as relações cotidianas entre escravos, senhores e libertos, recolocando a importância do paternalismo como mecanismo de poder senhorial. Assim, a autora contrapõe-se à visão dicotômica e antagônica da relação escravista sem, contudo, desconsiderar o uso da violência pelos senhores, como meio para manter a disciplina, e o da revolta pelos escravos, para negar a sua condição de coisa. Sustenta que apesar de ter existido a violência, os castigos corporais não faziam parte da vida diária do escravo. Seria o último recurso, quando não se conseguia manter a disciplina.

Para Mattoso (2003, p. 116-117), as relações escravistas teriam se baseado em métodos mais sutis de dominação e resistência. Os senhores faziam uso de seu caráter patriarcal e paternalista para persuadirem os escravos a se adaptarem às condições de trabalho, buscando ligá-los a ele por laços afetivos. Os cativos, por sua vez, mesmo reduzidos à condição de coisas pelos senhores, não deixaram de ser seres humanos. Contrariando as análises marxistas, a historiadora afirma que eles eram conscientes e tinham por objetivo facilitar suas vidas no cativeiro. Assim, o mesmo paternalismo usado pelo senhor, também era utilizado por muitos dos cativos, que encontravam no tripé humildade, fidelidade e obediência uma forma sutil de resistência à desumanização, conquistando direitos e espaços de autonomia.

Para o escravo, como se vê, a obediência não é totalmente fruto da necessidade gratuita. Certamente que satisfaz ao senhor, mas o escravo vê nela uma necessidade que o leva bem adiante do gesto cotidiano [...]. Trata-se da única estratégia possível, pois o negro, para subir na escala social e conquistar sua parcela de vida privada, precisa utilizar os valores da sociedade branca de adoção. Resguardado na obediência, ele poderá recriar seu mundo destruído, um universo novo com as cores da terra brasileira, mas bem seu. Uma vez aceita como necessidade tática, a obediência precisa ser moeda sonante no dia-a-dia. O escravo deverá fazer um triplo aprendizado antes de colher os primeiros resultados de sua aparente docilidade: aprender a língua do senhor, rezar ao Deus dos cristãos e saber executar um trabalho útil. (MATTOSO, 2003, p. 111-112)

No que tange à perda de identidade dos africanos transplantados para o Brasil, eles souberam recriar suas identidades, na medida em que se estabeleciam vínculos econômicos, afetivos e religiosos entre os cativos recém-chegados e a comunidade escrava (MATTOSO, 2003, p. 105). Para a pesquisadora, a personalidade social do cativo não deve ser encontrada nos laços matrimoniais por dois motivos: o número de ho- 
mens era superior em relação ao de mulheres e os senhores não viam "com bons olhos os casamentos entre escravos". Assim,

[...] Pode-se imaginar, por exemplo, que, se ele estabelece laços familiares entre os novos e os antigos, o africano poderá reencontrar essa referência de linhagem tão necessária. [...] O pivô das novas sociedades não deverá ser procurado nas relações matrimoniais, mas antes nas relações sociais de tênue vizinhança, de grupo de trabalho, do lazer e outras associações de tipo diverso. (MATTOSO, 2003, p. 105)

O cativeiro não era apenas um lugar de trabalho, castigos físicos e vigilância constante. Havia momentos para a realização de práticas culturais e manifestações de tradição e costumes. Reis (1983, p. 107) afirma: "As evidências são claras: o escravo africano soube dançar, cantar, criar novas instituições e relações religiosas e seculares [...]”. Em Negociação e conflito, Silva e Reis (1989) perceberam a existência da negociação como uma posição intermediária entre a submissão total e a agressividade cega do escravo. Assim o cativo enxergava no compromisso com o sistema, uma forma de superar as adversidades, podendo abrir espaço para construir o próprio viver. Reis (1988) enfatiza ainda que os escravizados aproveitavam-se das divergências entre os brancos sobre acabar ou não com os ritos de origem africana, estabelecendo alianças que garantissem a manutenção de suas práticas religiosas. Tais alianças foram essenciais para a aproximação entre escravizados e senhores.

Além dos trabalhos de Mattoso e Reis, destacam-se nesse período os trabalhos de Slenes (1986) que em Na senzala, uma flor discutiu a constituição da família escrava à luz da cultura africana, no Sudeste escravista do século XIX; Florentino e Goes (1997) debruçaram-se sobre o tráfico negreiro; Vainfas e Souza (1998) pesquisaram o processo de conversão dos escravos ao catolicismo. Enfim, as pesquisas iniciadas nos anos 1980, trouxeram novas abordagens sobre a escravidão. Em reação à visão reificadora do africano e a quase exclusividadedo fator violência nas relações escravistas, buscaram mostrar a complexidade da vida escrava no Brasil,onde negro, sujeito da história, resiste e busca as mais variadasestratégias para alcançar a liberdade e/ou amenizar a sua dura vida do cativeiro.Contudo, as mudanças ocorridas no campo da pesquisa pouco repercutiram nos manuais didáticos de História, que, junto a outros meios de circulação de representações do conhecimento histórico, como os meios de comunicação de massa, têm contribuído para a permanência de uma visão tradicional sobre a escravidão no imaginário social.

Nesse sentido, aceitar que a ideologia veiculada pelo livro didático e os meios 
de comunicação de massa seja apropriada e reproduzida de forma integral pelos sujeitos consumidoresseria declarar a sua alienação completa.

A apropriação, tal como a entendemos tem por objetivo uma história social, das interpretações, remetidas para as suas determinações fundamentais (que são sociais, institucionais, culturais) e inscritas nas práticas específicas que as produzem. Conceder deste modo atenção às condições e aos processos que, muito concretamente determinam as operações de construção do sentido (na relação de leitura, mas em muitas outras também) é conhecer, contra a antiga história intelectual, que as inteligências não são desencarnadas, e, contra as correntes de pensamento que postulam o universal, que as categorias aparentemente mais invariáveis devem ser construídas na descontinuidade das trajetórias históricas. (CHARTIER, 1990, p. 26-27)

Pela perspectiva de Chartier (1990), entende-se que a recepção das representações sociais pelos sujeitos não ocorre de forma passiva e inalterável, ou seja, não exclui a possibilidade de divergências na interpretação. Nesse sentido, considera-se que interiorização que se faz de determinada mensagem pode sofrer a interferência de elementos histórico - culturais, sociais, materiais, de costumes, entre outros.Isso significa dizer que a interpretação e apropriação de mensagens e representações podem ocorrer de formas diferenciadas pelos sujeitos, gerando a criação de significados e ações distintas.

Contudo, não se pode negar também, que muitos indivíduos tendem a reproduzir os conteúdos veiculados pelos meios de comunicação - televisão, revistas, rádio, internet, cinema, vídeo e computadores - e é nesse sentido que o professor de História possui um papel pedagógico importante. Em um cotidiano dominado pelas imagens, as pessoas têm mais acesso à História por novelas, minisséries e filmes do que pela leitura de textos e livros, uma vez que essas mídias também sugerem interpretações sobre culturas, fatos e personagens históricos.

Levando-se em consideração os objetivos desta pesquisa, pensa-se no efeito produzido principalmente pelas imagens, no que diz respeito às representações sobre o negro e sua trajetória na História do Brasil. Filmes, fotografias e pinturas devem ser tratados como fontes para a formação histórica em sala de aula, pois seu conteúdo fornecem elementos para compreensão da sociedade na qual foi produzido: suas ideias, valores e, principalmente, no caso deste trabalho, sua posição em relação a outras culturas. 


\section{A Experiência Didática em sete módulos}

Primeiro Módulo. Para estudar e compreender o racismo do modo como ele se apresenta hoje, é necessário retomar um passado distante, buscando localizar a sua origem, seu processo de construção e suas ressignificações. Para isso, propõe-se a utilização do texto O futuro é branco, de Giralda Seyferthé (2014), bem como o quadro Redenção de Can, de 1895, do pintor espanhol Modesto Brocos y Gómez (1852-1936).

Iniciou-se a aula informando aos estudantes que seria realizado um estudo sobre a tese do branqueamento no período da Primeira República da História do Brasil para, em seguida, questionar-se o que sabiam sobre o assunto, se já tinham ouvido falar, lido sobre ou estudadoo artista Modestos Brocos y Gómez e uma de suas obras mais famosas, Redenção de Can. Após se manifestarem sobre as questões, foi projetada a imagem da obra na parede da sala. Solicitou-se aos estudantes que observassem a tela por um alguns instantes, prestando atenção aos seus detalhes e levantassem hipóteses sobre ela. Foi enfatizado que a obra de arte é uma interpretação do artista sobre a realidade, uma representação subjetiva, relacionada ao modo como se vê e interpreta aquilo que está sendo retratado. Comentou-se ainda, que essa interpretação está associada ao seu estilo e ao movimento artístico no qual o artista está inserido. Para que os estudantes se tornassem aptos a construir uma interpretação da obra, foramdisponibilizados a eles os textos O futuro era brancoe a biografia de Modestos Brocos y Gómez (2014). Fez-se uma adaptação no texto O futuro é branco, antes de entregá-lo aos estudantes, retirando-lhe os dois primeiros parágrafos e o penúltimo, pois eles continham interpretações da autora sobre a tela, o que inviabilizaria o desenvolvimento de reflexões próprias dos estudantes. Antes de iniciar a leitura, foram entregues dicionários aos estudantes, pois havia a possibilidade de que haveria palavras desconhecidas. Para a análise da imagem, propuseram-se as seguintes questões:

1) Há alguma relação entre a obra e o contexto em que foi produzida? Qual?

2) Como os personagens estão representados na cena e qual a relação entre eles?

3) Na opinião do grupo, qual a posição do autor em relação à cena retratada?

A dinâmica deve seguir a seguinte proposta: disponibilizar uns 10 minutos para que os grupos discutam entre si as questões apresentadas e cerca de 20 minutos para que as respondam, apresentando oralmente o que cada um escreveu. Caso seja observada alguma distorção entre os relatos e o que se conhece das obras, o professor deve tomar a palavra brevemente e inserir elementos que aproximem os estudantes de 
interpretações lógicas da obra. É importante que percebam o progressivo branqueamento das gerações na família representada.

Segundo Módulo. A aula iniciou-se com uma breve retomada das teorias raciais do século XIX e, em seguida, foi realizada a distinção entre os conceitos de raça e etnia. Pediu-se também para que os estudantes lessem o texto O que é raça? O que é etnia? (UNFPA, 2014) e respondessem às seguintes questões: 1) Identifique no texto os conceitos de raça e etnia, apontando a diferença entre eles. 2) Quais são as consequências da discriminação racial e de que formas elas se manifestam?

Solicitou-se aos estudantes que socializassem as respostas, levando outros questionamentos. Os estudantes foram provocados para que percebessem, com base nas informações do texto, que o conceito de raças foi criado para justificar a dominação de determinados povos sobre outros.

Terceiro Módulo. Nessa etapa, iniciou-se a aula perguntando-se aos estudantes o que sabiam sobre a origem das favelas em nosso país. Deixou-se que expusessem seus conhecimentos. Após esse momento de interação, foi realizada uma contextualização histórica da situação do negro, no início da Primeira República (1889 - 1930). Ressaltou-se que a falta de políticas governamentais para inseri-lo no mercado de trabalho e na vida social como homem livre deixou a ele poucas opções de sobrevivência. Nessa parte da explicação, o professor pesquisador retomou a primeira aula da sequência, comentando que o incentivo à entrada massiva de imigrantes, principalmente europeus, além de objetivar o branqueamento da população, prejudicava ainda mais o negro no pleito por uma vaga no mercado de trabalho.

Comentou-se que a mão de obra imigrante era considerada muito mais qualificada para o trabalho assalariado, sendo esta uma das causas da marginalização do negro. Explicou-se que na cidade do Rio de Janeiro, os bairros pobres eram habitados por ex-escravos e trabalhadores sem qualificação ou ocupação profissional definida. Ressaltou-se que, nessa época, a elite brasileira tinha como intenção apagar os indícios da escravidão, modernizando as grandes capitais do sudeste cafeeiro,o que fez com que a população pobre fosse empurrada de forma truculenta para os morros da cidade, para a periferia (CATELLI JÚNIOR, 2009, p.112).

Em seguida, foi realizada uma breve contextualização da etimologia da palavra favela, relacionando-a com a literatura e a história, por meio do texto: De Canudos para o Brasil: a história da palavra favela (RODRIGUES, 2014). Feita a contextualização, foi apresentada aos estudantes a letra da canção $A$ favela vai abaixo, de 1928 (SINHÔ, 2014). Explicou-se que a canção foi escrita dentro do contexto comentado e, em seguida feita a primeira audição. A canção foi escutada pelo menos duas vezes. Os 
estudantes foram orientados para que a ouvissem atentamente e também estimulados a exporem as sensações transmitidas pela música, o possível significado da letra e os instrumentos utilizados (CATELLI JUNIOR, 2009, p. 122-123).

A etapa seguinte consistiu em ouvir a canção pela segunda vez, atentos aos detalhes que poderiam ter passado despercebidos. Foi solicitado que, primeiramente, fizessem um levantamento das palavras desconhecidas e pesquisassem o seu significado no dicionário, para, em seguida, dedicarem-se à interpretação da letra. Explicou-se que a canção é constituída por uma linguagem poética, repleta de símbolos, que não têm como objetivo a informação. Após a interpretação, os estudantes realizaram a leitura da biografia do compositor e o levantamento de informações sobre a canção. Para finalizar a análise, foi solicitada aos estudantes, como atividade extraclasse, a produção de um texto interpretativo,orientado pelos seguintes critérios:

1) relacionar a canção com o contexto histórico da cidade do Rio de Janeiro, durante as primeiras décadas do século XX;

2) mencionar a posição do compositor em relação ao tema referido na canção;

3) realizar uma pesquisa e mencionar exemplos, na redação, inclusive se ainda ocorrem contemporaneamente, com a população mais pobre, fatos parecidos com o abordado pela canção e pelos textos.

Ao término das atividades, solicitou-se que alguns estudantes, na condição de voluntários, expusessemas informações encontradas. No percurso das exposições, promoveu-se uma discussão sobre o nascimento do samba. Foi destacado que, a população moradora da periferia era, na sua maioria, analfabeta e estava excluída do direito de decidir de maneira diretasobre o destino do país, e que o samba servia como forma de protesto, além de denunciar o descaso do poder público com as classes menos favorecidas.

Quarto Módulo. Nessa aula, fez-se uso do datashow para apresentar imagens de filmes previamente selecionadas. O objetivo foi apresentar aos estudantes alguns dos vários elementos que constituem a linguagem cinematográfica, tais comomovimentos de câmera, fotografia, figurino e trilha sonora, e comosão utilizados de maneira intencional pelo diretor do filme, no intuito de atribuir determinado sentido à cena, ou causar determinadas sensações (Essa etapa durou uma aula).

Iniciou-se a apresentação explicando as diferenças entre a linguagem escrita e a linguagem cinematográfica, com o objetivo de mostrar aos estudantes que a última é formada pela combinação de vários elementos, e que constitui a estética do filme veiculando, ao mesmo tempo, mensagens. Durante a apresentação, os estudantes foram instigados a fazer inferências sobre os possíveis significados desses elementos.A 
finalidade dessa atividade era, portanto,a de queos estudantes compreendessem que a combinação desses vários elementos constitui a estética do filme e étambém veículo de mensagens.

Quinto Módulo. O professor iniciou a aula retomando brevemente o conteúdo visto anteriormente. Em seguida, apresentou à turma, como proposta de trabalho, a análise da representação do negro em três filmes nacionais. As produções correspondiam a períodos diferentes da História do Brasil: o Governo Vargas, a República Populista e a Ditadura Militar. Para essa atividade, foram selecionados: O Despertar da Redentora, de 1942, média metragem, com duração de 21 minutos; um trecho de Orfeu do Carnaval, de 1958, com duração de 10 minutos e 20 segundos; um trecho de Rio Babilônia, de 1982, de onze minutos e um segundo. Para os dois últimos filmes foram selecionados trechos, poispor serem produções antigas, a exibição de sequências longas poderia logo dispersar a concentração dos estudantes. O objetivo era conduzi-los a analisar e identificar a representação estética do negro em filmes nacionais produzidos em diferentes períodos da história do País, buscando identificar também estereótipos do negro nos filmes nacionais com base na analogia de João Carlos Rodrigues (1988).

Feita a apresentação da proposta de trabalho e dos filmes a serem analisados, a turma foi dividida em grupos de cinco estudantes, encaminhados ao laboratório de informática para levantamento de informações básicas sobre as obras enfocadas, tais como: diretor, ano de produção, sinopse do enredo, contexto histórico e escola cinematográfica a que estavam filiadas. Antes da apresentação fílmica, foi entregue aos estudantes um roteiro de observação. Explicou-se que o objetivo do roteiro de análise era o de direcionar o olhar deles para os aspectos considerados mais importantes, visto que essa prática ajuda a construir uma leitura da obra. Solicitou-se que não fizessem anotações durante a exibição, mas sim ao final, pois isso poderia desviar a atenção de aspectos relevantes da produção. O roteiro de análise continha as seguintes questões:

1) Há personagens negros no filme? Que papéis representam?

2) Há personagens negros estereotipados? Quais?

3) Qual a mensagem principal da obra?

Concluída a projeção do filme e o tempo para as anotações, solicitou-se que os mesmos expusessem suas conclusões ao restante da turma.

Sexto Módulo. Na aula seguinte, foi explicado que seriam realizadas leituras e discussões de textos com a finalidade de torná-los aptos a ver de forma mais critica o filme Besouro (2009), produção que seria apresentada na íntegra posteriormente. Em seguida, solicitou-se que lessem um trecho do artigo de José Murilo de Carvalho (1997), abordando o conceito de coronelismo e as formas de barganha entre os coro- 
néis e o governo durante a Primeira República (1889-1930). Explicou-se que a escolha do texto deve-se ao fato de o coronelismo ter ocorrido no período representado pelo filme. A seguir, questionou-se oralmente se já haviam assistido ou ouvido falar ou sabiam de algum fato relacionado ao lendário capoeirista Besouro.

Após a leitura, discutiu-se o seguinte ponto: O que foi o coronelismo e como funcionava na prática?

Ao final das discussões,concedeu-se um tempo para que os estudantes registrassem as suas conclusões. Solicitou-se a um representante de cada grupo que expusesse as conclusões da equipe.

O objetivo era que percebessem que os coronéis tinham muita influência sobre o voto dos eleitores, durante a Primeira República, pois a grande maioria da população brasileira morava no campo e era analfabeta. Também buscou-se mostrar que a política praticada na época ficava restrita aos interesses de uma minoria, constituída por políticos e fazendeiros, e que, para mantê-la, ocorriam trocas de favorde toda ordem, desde o controle de cargos públicos até a realização de mínimos benefícios.

Destacou-se ainda que, para a maioria da população, o ato de votar era visto com indiferença. O povo, em sua maioria, não tinha consciência de sua importância e a política era usada para a manutenção dos interesses de uma elite, que pouco se importava com as mazelas sociais por que passava a maioria da população.

Em seguida, o professor pediu que lessem o texto Produção do filme Besouro (YUMPU, 2014), síntese da biografia do cineasta João Daniel Tikhomiroff e de uma entrevista em que ele relata algumas informações sobre o processo de produção do filme. Também solicitou-se que lessem o texto historiográfico com o título O capoeira besouro mangangá: alguns aspectos culturais do recôncavo da Bahia (1890-1930), do historiador Antônio Liberac Cardoso Simões Pires (2007), baseado na história oral e em registros policiais sobre da vida de Besouro. Foisolicitado aos grupos que comparassem os textos sobre a representação fílmica e historiográfica, discutissem e, em seguida, expusessem suas conclusões.

Para Napolitano (2011, p. 85), utilizar textos de apoio relacionados ao filme é uma prática importante, pois oferecem subsídios para problematizar e levantar questões sobre o conteúdo veiculado, enriquecendo a aprendizagem do estudante. Acrescenta também, que a utilização de "textos e documentos em outra linguagem [...] é especialmente útil para provocar no aluno certo distanciamento do impacto inicial, de ordem cognitiva e ideológica, que os filmes costumam causar nos espectadores mais envolvidos".

Ao final, os estudantes foram informados de que no encontro seguinte as cinco 
aulas do período seriam ocupadas com a disciplina de História para a projeção do filme e término das atividades organizadas para a sequência. Para isso, o empréstimo das aulas e a disponibilização e organização dos equipamentos já havia sido organizada com a supervisão e demais professores.

Sétimo Módulo. Iniciou-se a aula com a retomada breve dos conteúdos da aula anterior. Antes da projeção, houve a entrega da sinopse, da ficha técnica e de um roteiro para análise fílmica, que serviram para estabelecer parâmetros de observação sobre questões interpretativas, como por exemplo:

1) Em que local e época se desenvolve a história contada pelo filme?

2) Há personagens negros no filme? Como são representados?

3) Há personagens negros estereotipados? Quais?

4) Qual é a mensagem principal da obra?

Antes do início da exibição do filme, os estudantes foram novamente lembrados para não fazerem anotações durante a apresentação, e foram feitas poucas e breves pausas durante a mesma (já calculadas e mencionadas de antemão), para destacar os aspectos mais importantes.

Finalizada a exibição, questionou-se a turma com base nas questões do roteiro de análise. Solicitou-se que respondessem por escrito às questões e que expusessem suas conclusões para os colegas. Todos os membros do grupo foram incentivados a fazerem considerações complementares durante a exposição. Os estudantes ainda foram indagados se haviam notado diferenças na representação do negro em relação aos filmes anteriores. Nesse momento, houve a intervenção do docente, quando necessário, confirmando, confrontando dados, concordando ou discordando com o que estava sendo exposto.

\section{Considerações Finais}

A presente proposta busca compreender como os estudantes apropriam-se dos conteúdos étnicos sobre o negro, sobretudo os veiculados por filmes, discutindo a importância do seu uso em sala de aula, pois se deve considerar a similaridade da escola e do cinema enquanto recintos de socialização. Nesse sentido, o professor deve considerar que a escola não é o único local onde se ensina História, e que as mídias também sugerem informações sobre fatos, contextos e personagens as quais incitam a pensar sobre diferentes espaços e culturas.

A sequência didática apresentada tem a intenção de contribuir para a interação entre professores e estudantes, oportunizando momentos de reflexão e 
crítica sobre a forma como o negro brasileiro tem sido representado nos meios de comunicação, sobretudo no cinema. Espera-se, que esta proposta possa contribuir, enquanto material pedagógico, para a promoção de discussões e reflexões sobre as relações raciais no ambiente escolar, podendo servir como um produto educacional capaz de contribuir para a formação de valores e atitudes de respeito à diversidade cultural e étnica. Nesse sentido, deve-se levar em consideração a capacidade que o cinema tem de registrar o passado, com seus contextos e vivências, sua propensão para fixar imagens de determinados períodos e grupos sociais. Essas características validam-no enquanto objeto de análise para compreensão de como a imagem de "outro" é construída e porque é representada de determinada maneira, auxiliando os estudantes a compreenderem melhor o mundo em que estão inseridos.

\section{Referências}

ITAÚ CULTURAL- Enciclopédia. Biografia de Modestos Brocos Y Gomes. Disponível em: <http://www. itaucultural.org.br/ aplicExternas/enciclopedia_IC/ index.cfm? fuseaction $=$ artistas_biografia\&cd_verbete $=2830 \& c d \_i d i o m a=28555>$.Acesso em: 3 ago. 2014.

BRASIL. Lei no. 10.639 de 09 de janeiro de 2003. Inclui a obrigatoriedade da temática "História e Cultura Afro-Brasileira" no currículo oficial da rede de ensino. Diário Oficial da União, Brasília, 2003.

BRASIL.Secretaria de Educação Fundamental. Parâmetros Curriculares Nacionais: história e geografia. Rio de Janeiro DP\&A, 2000.

BROCOS y GOMES, M. Redenção de Can. 1895. Disponível em: <http://www. revistadehistoria.com.br/secao/perspectiva/o-futuro-era-branco >. Acesso em: 3 ago. 2014.

CARVALHO, J. M. de. Cidadania no Brasil: o longo caminho. 3. ed. Rio de Janeiro: Civilização Brasileira, 2002.

CARVALHO, J. M. de. Mandonismo, coronelismo, clientelismo. Uma discussão conceitual. Rio de Janeiro, vol. 40 n. 2, 1997. 
CATELLI JUNIOR, R. Temas e linguagem da História: ferramentas para sala de aula no ensino médio. São Paulo: Scipione, 2009.

CHAlHOUB, S. Visões da liberdade. São Paulo, Companhia das letras, 1990.

CHARTIER, R. A história cultural: entre práticas e representações. Tradução: Maria Manuela Galhardo. Lisboa: DIFEL,1990.

FLORENTINO, M.; GOÉS, J. R. Paz nas senzalas: famílias escravas e tráfico Atlântico. Rio de Janeiro, c.1790 -c. 1850. Rio de Janeiro: Civilização Brasileira, 1997.

FONSECA, T. N. de L. e. História e ensino de história. Belo Horizonte: Autêntica, 2006.

FREYRE, G. Casa Grande \& Senzala: formação da família brasileira sob o regime da família patriarcal. 19 ed. Rio de Janeiro, José Olympio, 1978.

MATTOSO, K. M. de Q. Ser escravo no Brasil. São Paulo: Brasiliense, 2003.

CIFRA ANTIGA. BLOGSPOT. Modernização da cidade do Rio de Janeiro. Disponível em: http://cifrantiga3.blogspot.com.br/2006/03/favela-vai-abaixo.html. Acesso em: 11 jun. 2014.

NAPOLITANO, M. Como usar o cinema em sala de aula. 5. ed. São Paulo: Contexto, 2011.

O DESPERTAR DA REDENTORA (1942). Direção, roteiro e montagem: Humberto Mauro. 21 min, INCE. Disponível em: <https:/ /www.youtube.com/watch? v= FRCWOm1vbs4>. Acesso em: 25 jul. 2014.

ORFEU DO CARNAVAL (1959). Direção: Marcel Camus. 102 min, Produção: SashaGordine [trecho: 10 minutos e 20 segundos]. Disponível em: <https:// www.youtube. com/watch?v=SVQ_9CuaDTc $>$. Acesso em: 25 jul. 2014.

PIRES, A. L. C. S. O capoeira Besouro Mangangá: alguns aspectos culturais do Recôncavo da Bahia (1890-1930). In: GODINHO, L. F. R.; SANTOS, F. J. S. (org.) Recôncavo da Bahia: educação, cultura e sociedade. Amargosa, Bahia: 
Ed. CIAN, 2007. p. 45-49. Disponível em: < http://www.ufrb.edu.br/bibliotecacfp/.../livros... reconcavo-da-bahia.../download $>$. Acesso em:2 jul. 2014.

YUMPU. Produção do filme Besouro. Disponível em: <https://www.yumpu.com/pt/ document/view/12473136/mixer-miravista-e-globofilmes-apresentam-um-filme-de -besouro/ 5>). Acesso em: 2 jul. 2014.

REIS, J. J. Poderemos brincar, folgar e cantar ...: O protesto escravo nas Américas. Afro-Ásia, v.14, p. 107-20, 1983.

REIS, J. J. e SILVA, E. Negociação e conflito: a resistência negra no Brasil escravista. São Paulo: Companhia das Letras, 1989.

RIO BABILÔNIA (1982). Direção, argumento e roteiro: Neville Almeida. 115 min, Centro de Produção e Comunicação LTDA. [trecho de 11 min. e 1 seg]. Disponível em: <https://www.youtube.com/watch?v=-rEc_Qm_sxk>. Acesso em: 25 jul. 2014.

RODRIGUES, S. De Canudos para o Brasil: a história da palavra favela. Disponível em: $<$ http://veja.abril.com.br/blog/sobre-palavras/curiosidadeetimologicas/favela-decanudos-para-o-brasil/>. Acesso em: 10 jul. 2014.

SANT' ANA, A. O. de. História e conceitos básicos sobre o racismo e seus derivados. In: MUNANGA, K. (org.). Superando o racismo na escola. Brasília: Ministério da Educação, Secretaria de Educação Continuada, Alfabetização e Diversidade, 2005, p. 39-65.

SINHÔ. A favela vai abaixo. Disponível em: <https://www.youtube.com/watch?v= 7O8gifq8irg>. Acesso em: 5 ago. 2014.

SLENES, R. W. Na senzala uma flor: esperanças e recordações na formação da família escrava, Brasil, Sudeste, século XIX. Rio de Janeiro: Nova Fronteira, 1986.

SEYFERTHÉ, G. O futuro é branco. Disponível em: <http://www.revistadehistoria. com.br/secao/perspectiva/o-futuro-era-branco $>$. Acesso em: 3 ago. 2014.

TIKHOMIROFF, J. D. Besouro. Mixer e Buena Vista Internacional, 2010. 1 videodisco (94 min). 
UNFPA. O que é raça? O que é etnia? Disponível em: www.unfpa.org.br/ Arquivos/ guia_racas.pdf. Acesso em: 12 jun. 2014.

VAINFAS, R.; SOUZA, Mariana de Mello e. Catolização e poder no tempo do tráfico: oreino do congo da conversão coroada ao movimento Antoniano, séculos XV - XVIII. Revista Tempo, Rio de Janeiro, n. 6, p. 96-118, 1998.

Recebido em: 15 maio 2015.

Aceito em: 24 maio 2015. 